\title{
The matricellular protein CCN1 induces fibroblast senescence and restricts fibrosis in cutaneous wound healing
}

\section{Joon-Il Jun and Lester F. Lau}

Nat. Cell Biol. 12 DOI:10.1038/ncb2070; published online 6 June 2010; corrected online, 12 November 2010

In the version of this article initially published online and in print, the labels BSA and CCN1 in Fig. 2a were swapped. The correct labelling is shown below. This error has been corrected in both the HTML and PDF versions of the article.

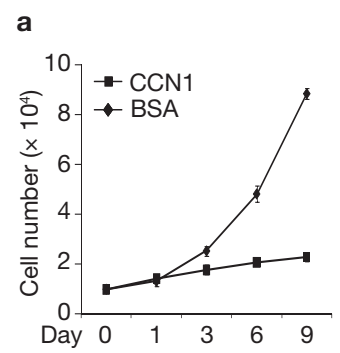

